\title{
Pudendal nerve testing
}

\author{
Viroj Wiwanitkit ${ }^{1,2,3}$
}

Accepted: 30 June 2016 / Published online: 6 July 2016

(C) Springer-Verlag Berlin Heidelberg 2016

\section{Dear Editor:}

The recent report on "Pudendal nerve testing" is very interesting [1]. Cooper et al. concluded that "Pudendal nerve testing does not contribute to surgical decision making following anorectal testing in patients with faecal incontinence [1]." Cooper et al. also questioned "the utility of this investigation [1]." In fact, pudendal nerve testing is a very classical physical examination and requires no cost for testing. Since it is a physical examination, it might be considered subjective, and the accuracy of the result also depends on the technique and experience of the practitioner $[2,3]$. As noted by Yip et al., "the technique is seldom taught and mastered in colorectal training programs," and this might be the cause that the practitioner cannot correctly perform the testing and destroyed the usefulness of "Pudendal nerve testing [4]."

\section{References}

1. Cooper EA, De-Loyde KJ, Young CJ, Shepherd HL, Wright C (2016) Pudendal nerve testing does not contribute to surgical decision making following anorectal testing in patients with faecal incontinence. Int J Colorectal Dis

2. Olson CH (2014) Diagnostic testing for fecal incontinence. Clin Colon Rectal Surg 27(3):85-90

3. Van Koughnett JA, da Silva G (2013) Anorectal physiology and testing. Gastroenterol Clin N Am 42(4):713-28

4. Yip B, Barrett RC, Coller JA, Marcello PW, Murray JJ, Roberts PL, Rusin LC, Schoetz DJ Jr (2002) Pudendal nerve terminal motor latency testing: assessing the educational learning curve: can we teach our own? Dis Colon Rectum 45(2):184-7

Viroj Wiwanitkit

wviroj@yahoo.com

1 Hainan Medical University, Haikou, China

2 Faculty of Medicine, University of Nis, Nis, Serbia

3 Bangkhae, Bangkok, Thailand 10160 